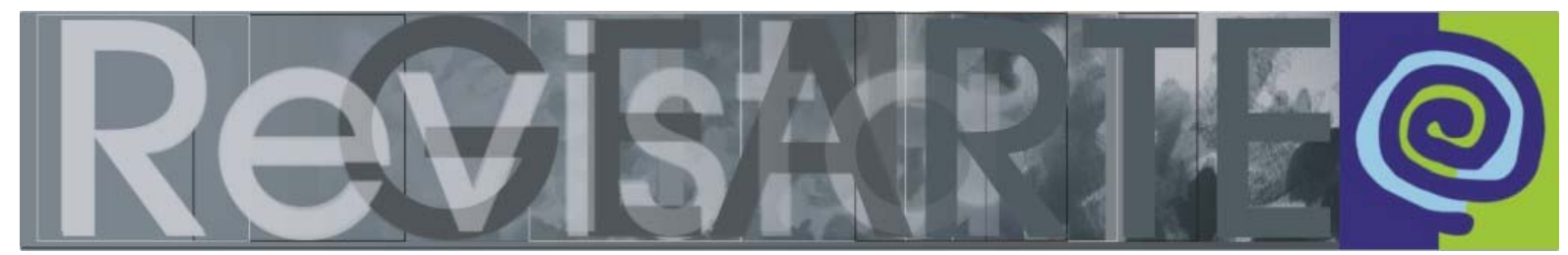

ISSN 2357-9854

\title{
Leitura visual e educação estética de crianças $^{1}$
}

\author{
Maria Helena Wagner Rossi (UCS - Brasil)
}

\begin{abstract}
RESUMO
Este artigo aborda relações entre leitura visual e educação estética de crianças. Traz exemplos de leituras de imagens em contexto escolar, analisando depoimentos de crianças para explicitar a natureza de sua compreensão estética. Tece críticas a abordagens que não respeitam a construção do conhecimento estético de crianças. Argumenta que a mediação estética pode ser adequada e significativa para as crianças da educação infantil e dos anos iniciais do ensino fundamental desde que considere a natureza do seu pensamento estético.
\end{abstract}

PALAVRAS-CHAVE

Leitura visual. Pensamento estético infantil. Educação estética de crianças.

\section{ABSTRACT}

This article discusses relations between children's visual reading and aesthetic education. Provides examples of image reading by students, analyzing testimonials from children to explain the nature of their aesthetic understanding. Criticizes approaches that do not respect the construction of aesthetic knowledge of children. It argues that the aesthetic mediation can be appropriate and meaningful for children in kindergarten and the early years of elementary school, since it considers the nature of his aesthetic thought.

KEYWORDS

Visual reading. Children's aesthetic thought. Children's aesthetic education.

Ainda é pertinente falar em leitura visual ou leitura de imagens? Há espaço para o ato de ler - que acompanha a humanidade em sua história - no ensino contemporâneo de arte? Há quem diga que isso é coisa do passado. Alguns autores rejeitam o uso do termo leitura no contexto da arte interativa, como Domingues (1997, p. 32), Couchot (1997, p. 142) e Oliveira (1999, p. 90). Os autores discutem sobre a natureza do visitante das instalações de arte, questionando as denominações de espectador e observador. No entanto, admitem, implicitamente, que algo se passa no encontro estético: "acesso à

\footnotetext{
${ }^{1}$ Este texto traz fragmentos das pesquisas realizadas na Universidade de Caxias do Sul: (a) $O$ desenvolvimento da apreciação estética: uma abordagem discursivo-cognitiva, que contou com a participação das bolsistas: Ângela C. Dalla Colletta, Isadora Demoliner e Mara A. Magero Galvani, com auxílio do CNPq. (b) A compreensão estético-visual na educação fundamental: um estudo longitudinal, com a participação das bolsistas: Ângela Grizon, Carmen Lúcia Capra e Rosane Gaiesky, com auxílio do CNPq e da FAPERGS.
} 
obra" para Domingues; "apreensão/relação" para Oliveira; "participação - que não impede a contemplação e a meditação" - para Couchot.

Ao questionar o termo leitura, diz Domingues:

O espectador não está mais diante da "janela", limitado pelas bordas de uma leitura, com pontos de vista fixos. Ou seja, não é mais alguém que está fora e que observa uma "obra aberta" para interpretações. Com a interatividade própria das tecnologias digitais e comunicacionais surge a metáfora da "porta aberta". $(1997,23)$.

Independente das questões terminológicas discutidas pelos autores, o que interessa aos profissionais que se empenham em promover a educação estética por meio da leitura visual são outras indagações, tais como: O que acontece no encontro estético? Que transformações são possibilitadas pela arte? Que contribuições a leitura estética tem na vida de seus alunos? O que é "saber arte" para a criança? Como os estudantes leem arte e imagens? Que significados podem ser construídos "para si mesmos e para o mundo" (OLIVEIRA, 1999, p. 98), durante a leitura visual?

Para contribuir nessa discussão, este artigo trata da leitura visual e suas relações com a educação estética de crianças, trazendo exemplos de leituras em contexto escolar - mas que podem ser estendidos a contextos museais para se pensar sobre o encontro estético, seja com a obra tradicional, seja com a contemporânea. Como diz Debray (1993, p. 215), "do mesmo modo que a imprensa não suprimiu de nossa cultura os provérbios e anexins medievais, [...] assim também a televisão não nos impede de ir ao Louvre - muito pelo contrário - e o departamento das antiguidades egípcias não está fechado para o olhar formado pela tela". Por isso, o que interessa aqui são as possíveis transformações que a leitura visual engendra no processo de desenvolvimento do pensamento estético do leitor - isto é, na educação estética - no museu, em exposições, na interatividade ou mesmo na sala de aula com imagens em papel ou em data show ${ }^{2}$. Assim pensando, é possível considerar "leitura" no mesmo

\footnotetext{
${ }^{2} \mathrm{Em}$ nossas pesquisas não houve diferenças na estrutura do pensamento estético evidenciado pelos estudantes diante das imagens fixas e da participação na instalação interativa. (ROSSI, 2003).
} 
sentido de outros termos usados atualmente, como: apreensão, acesso, apreciação, fruição, recepção, compreensão, atribuição de sentido...

Debray (1993) diz que o olhar não é algo passivo; é ação que coloca em ordem o visível, organizando a experiência humana. E é por isso que dizemos que leitura visual e discussão estética são - ainda hoje - pertinentes na educação dos estudantes, mesmo que sejam eles o que conhecemos como "alunos zappiens"3.

Os alunos zappiens têm características diferentes dos da geração anterior: são mais ativos e colaborativos nos modos de aprender, preferem abordagens não lineares, suas habilidades são mais icônicas do que relacionadas ao texto escrito, entre outras. Um dos criadores desse termo diz que a aprendizagem no contexto do homo zappiens "tem evoluído a partir da atividade individual de internalizar o conhecimento para um processo social de externalização do conhecimento" (VEEN, s/d, p. 3). Tais características são bemvindas nas aulas de leitura de imagem e discussão estética. Ao mesmo tempo, esse modo de construir conhecimento pode ser facilmente acolhido na sala de aula, como se verá a seguir, a partir de exemplos de depoimentos de alunos frente a imagens. Uma abordagem que vai ao encontro dos modos de ser do aluno zappiens torna a aula interessante e motivadora - que é uma constante busca de professores cujos alunos mostram maior capacidade de concentração ao lidar com as tecnologias do que com as atividades tradicionais. Esse aluno é avesso à passividade, às respostas únicas e fechadas, ao que não lhe desafia. Então a natureza "aberta" da arte permite uma aproximação aos seus interesses e modos de pensar.

Isso não significa que os estudantes da educação básica podem aprender qualquer coisa a qualquer tempo ou que qualquer leitura de imagem serve para todos. Mesmo o estudante zappiens tem características cognitivas e socioculturais próprias, as quais são evidenciadas nos diversos momentos de

\footnotetext{
${ }^{3}$ Termo que caracteriza a geração nascida após a década de 80 (VEEN; VRAKKING, 2009), também conhecida como geração $\mathrm{Y}$, de rede ou instantânea e nativos digitais.
} 
seu processo de escolarização. Essas características deveriam ser o pano de fundo de nossas ações na leitura de imagem/arte.

Uma análise, mesmo que superficial, mostra que inúmeros materiais de orientação de leitura visual e educação estética disponíveis no país não consideram as reais condições de leitura dos estudantes, isto é, seus limites e suas possibilidades. Impelidos a Ihes propiciar uma formação cultural, muitas vezes não respeitamos a natureza do seu pensamento estético ${ }^{4}$, exigindo uma compreensão que eles não alcançam. Além disso, muitos professores e mediadores ainda acreditam que informações históricas, dados biográficos ou aspectos formais (elementos e princípios da composição) são as coisas mais importantes na educação estética dos estudantes. Há, ainda, a crença de que os pequenos podem - e devem - compreender as intenções dos artistas ao criarem suas obras 5 e os que "imaginam" que as crianças compreendem arte como os adultos. Enfim, são muitos os equívocos possíveis no campo da leitura visual quando não se leva em conta os processos de construção de conhecimento estético dos estudantes em cada momento do processo de escolarização e em cada contexto.

Ao discutir alguns aspectos da compreensão estética de crianças esperase contribuir para a revisão de abordagens inadequadas. Concordamos com Parsons quando alerta que é um erro comparar a compreensão estética da criança com a do adulto: "É puro romantismo pensar que a sua experiência da arte é equivalente a dos adultos, ou que as suas obras estão igualmente carregadas de sentido." (1992, p. 44). Segundo o autor há uma série de perspectivas sobre a arte que as crianças não têm acesso e "o desenvolvimento estético consiste precisamente na aquisição destas perspectivas". Por isso, no contexto da educação estética, uma análise do que pensam os alunos sobre arte

\footnotetext{
${ }^{4}$ Sobre características do pensamento estético-visual de estudantes em contexto brasileiro, ver Rossi (2003).

${ }^{5}$ A necessidade de conhecer a intenção do artista na produção da obra é uma característica da compreensão estética do Nível III da classificação de Rossi (2003). Nesse caso, o leitor acredita que os sentidos são determinados pelo artista, cabendo a ele apenas decifrá-los. Essa compreensão não aparece antes dos 12 anos nas pesquisas de HOUSEN (1983), PARSONS (1992) e ROSSI (2003). No entanto, em estudo longitudinal com leitura e discussão estética que proporcionou familiaridade com arte - essa ideia surgiu aos nove anos (ROSSI, 2005).
} 
é "uma ferramenta útil para os professores" (PARSONS; FREEMAN; 2001, p. 73).

\section{Leitura de imagem e discussão estética com crianças}

Em contextos urbanos, desde cedo, grande parte das crianças têm contato com a linguagem visual, em embalagens, livros, revistas, outdoors, televisão, videogames, tablets etc. Mesmo antes de um ano de idade, bebês mostram uma destreza surpreendente com seus dedinhos na tela sensível ao toque dos tablets. Não se sabe ainda quais serão as consequências dessa precocidade, mas é evidente que os bebês zappiens estão vendo mais imagens e mais cedo do que era possível há poucos anos. Isso nos leva a rever os fundamentos epistemológicos da educação estética e a questionarmos: desde que idade se pode falar em leitura de imagem e educação estética? Sabe-se que o contato com imagens é importante no momento em que a criança está construindo a ideia do que é uma imagem e do modo como funciona a representação. Ela aprende a dar sentido ao que vê nas interações com o meio. Quando presencia os adultos comentando uma revista, folheando um livro ilustrado, conversando sobre uma imagem numa embalagem, no tablet, na TV... está aprendendo, à sua maneira, que imagem também se lê; que sentidos podem ser atribuídos a ela. Por isso, assim como a literatura deve estar presente no cotidiano escolar infantil, a leitura de imagens também deve estar, compartilhando tempos e espaços com a escuta de histórias, a música, o canto, o desenho, o manuseio de revistas e livros de narrativa visual... Assim, desde cedo, a criança se familiariza com textos de diversas naturezas, interagindo com contextos de leitura. Podemos supor, então, que a leitura de imagens tem início no primeiro ano de vida.

A partir dos quatro anos de idade a criança pode escutar histórias mais atentamente. Ouvir as narrativas dos colegas é algo interessante e, por isso, devem ser incentivadas a dialogar com eles. Segundo Fragoso (1998, p. 48), nessa idade as crianças "vão adquirindo as habilidades necessárias para compreender uma história (esquema cognitivo prévio que corresponde estreitamente às categorias básicas presentes em uma narração)". É comum que 
as narrativas inventadas sejam curtas e carregadas de imaginação, como se pode ver na leitura de Rua de Erradias, de Lasar Segall ${ }^{6}$, por crianças de quatro e cinco anos:

- As meninas querem ir passear.

- São bonecas com um espelho dentro de uma casinha.

- Eles querem ir para casa comer; estão com fome.

- É um monte de meninas olhando TV.

- As mulheres estão limpando a casa para não entrar nenhum bicho.

- As mulheres estão no caminhão; uma está sentada e outra de pé.

- Este aqui está saindo do ônibus. A mulher está dentro do ônibus. O ônibus tem a porta para entrar e aqui é a janela para olhar.

Qual é o papel do professor/mediador durante uma leitura como essa? Certamente não deveria ser o de desprezar falas dessa natureza para impor informações sobre o contexto da produção da obra, a interpretação mais conhecida (são prostitutas num prostíbulo) ou informações biográficas do artista (Lasar Segall nasceu na Rússia7), já que isso seria desconsiderar a natureza do pensamento estético da criança. Há que se ter em mente que informações sobre a obra, o artista ou o contexto podem não corresponder ao que a criança pensa sobre arte, isso é, às suas ideias estéticas. Freeman e Sanger (1995) dizem que as crianças, gradualmente, constroem "teorias" sobre arte e as usam para explicitar a sua compreensão. Os autores dizem que as pessoas adquirem teorias durante suas experiências cotidianas nas várias áreas do conhecimento, como na matemática, na linguagem, na física e também na arte. Essas "teorias" sobre a arte são feitas de ideias que elas adquirem/constroem durante as experiências cotidianas em seus encontros com trabalhos de arte. Às vezes, tais ideias podem parecer ingênuas ou em desacordo com o que supomos que as crianças deveriam saber. Se assim as considerarmos, privaremos a criança da possibilidade de filosofar sobre questões estéticas a seu modo.

\footnotetext{
6 A imagem pode ser vista em: <http://www.brasilartesenciclopedias.com.br/nacional/ segall_lasar01.htm>. Acesso em: 25 jul. 2015.

${ }^{7}$ Mirian Celeste Martins narra uma cena que exemplifica a desconsideração do pensamento estético infantil: ao mostrar imagens de obras de Lasar Segall para crianças entre três e quatro anos, a professora informa: "Lasar Segall nasceu na Rússia." Logo após uma criança comenta: "Ele nasceu na montanha Rússia!". Mas a fala da criança não foi comentada. (informação verbal, 2014).
} 
$\mathrm{Na}$ educação infantil não há propriamente uma discussão frente às imagens. As crianças se ocupam em falar, sem considerar o que ouvem dos colegas; falam mais para si do que para o grupo. Isso acontece porque sua perspectiva é mais pessoal e centrada do que a dos anos iniciais, o que dificulta a consideração e a coordenação dos múltiplos pontos de vista de uma situação ou objeto. Essa perspectiva pode gerar a "eleição" de partes do fenômeno, desprezando sua totalidade. É possível notar essa característica cognitiva no desenho infantil, quando a criança representa elementos isolados na folha de papel, desconsiderando a totalidade da cena - o que Luquet chamou de estágio da Incapacidade Sintética (LUQUET, 1981). Na leitura estética isso é visível quando a criança fixa a sua atenção em alguns aspectos, enquanto ignora outros, numa espécie de enumeração das coisas que vê. A leitura de Retrato de Julie Manet $^{8}$ por crianças de quatro e cinco anos exemplifica essa compreensão:

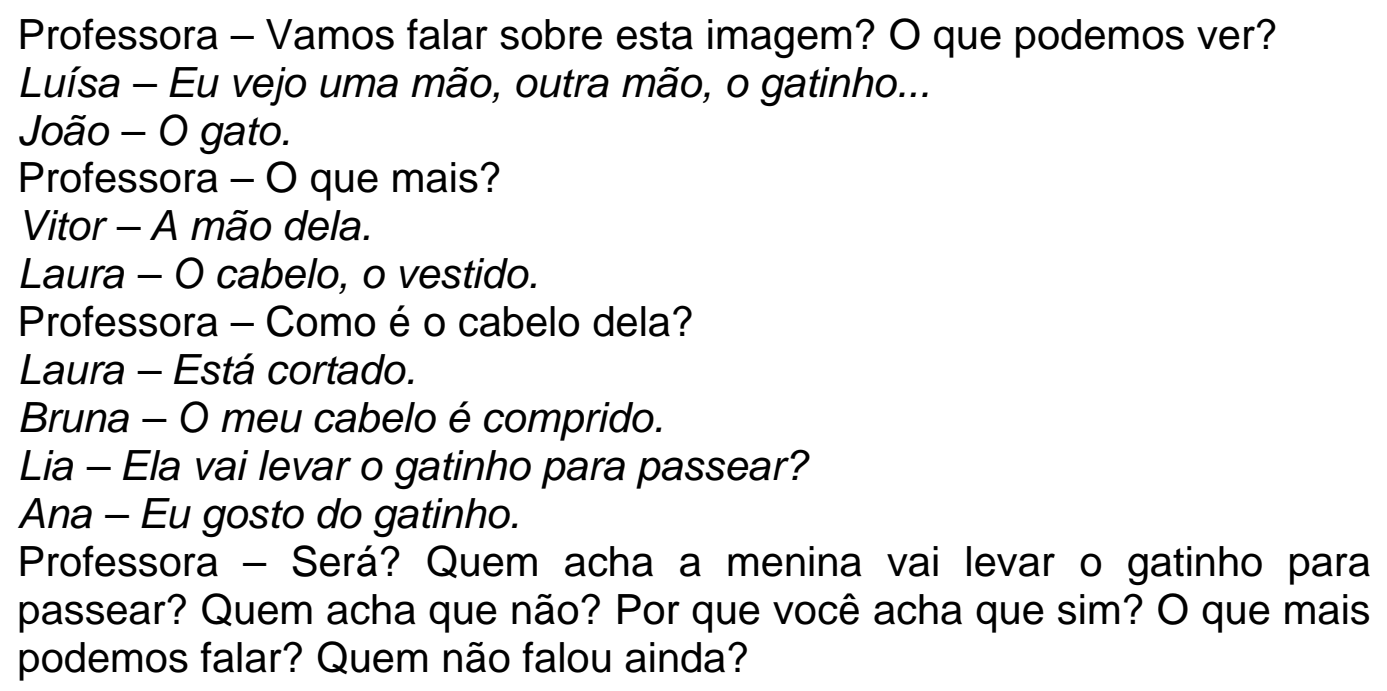

No julgamento estético, as crianças usaram critérios particulares e, então, a presença da cor preferida, do animal de estimação ou de algo com que ela se identifica determina a qualidade da imagem:

Professora - Esta imagem é boa? Vocês gostaram de ver? Por quê?

Lia - Esta é a mais bonita, porque tem a menina.

Joana - Porque tem o gatinho.

Vitor - Porque o gatinho está no colinho.

\footnotetext{
${ }^{8}$ Pierre-Auguste Renoir, Retrato de Julie Manet, 1887. Óleo sobre tela. Museu d'Orsay. A imagem pode ser vista em: http://www.musee-orsay.fr/es/colecciones/obras-comentadas/ pintura/commentaire_id/julie-manet-10656.html?tx_commentaire_pi1\%5BpidLi\%5D=509\&tx_co mmentaire_pi1\%5Bfrom\%5D=841\&cHash=05b256b879. Acesso em: 02 abr. 2014.
} 
Ana - Eu gostei mais desta por causa do gatinho.

Professora - Por isso a imagem é boa? Quem quer falar outra coisa?

Embora essas ideias possam não ser reconhecidas como válidas, podese dizer que constituem os primórdios do desenvolvimento estético. Nesse caso, a mediação deve oportunizar à criança oportunidades para expor ideias, dúvidas e descobertas, obter respostas às suas perguntas, dialogar com os pares, ouvir e ser ouvida, respeitar e ser respeitada... Se ela não for valorizada na expressão de suas ideias, num clima de confiança e respeito, tenderá a se retrair e a se calar. É nesse clima de confiança e respeito que o pensamento estético se desenvolve.

Quanto mais próximo dos anos iniciais, mais facilmente a criança tornase capaz de "calçar os sapatos dos outros" (KESSELRING, 2011), isso é, de assumir a perspectiva dos colegas. Essa característica proporciona uma nova possibilidade na leitura de imagens, tornando a discussão em aula mais rica; um considerando o argumento do outro. As crianças abordam "o todo" da imagem e se deliciam inventando narrativas mais longas e complexas envolvendo vários elementos da imagem, como se vê nas falas de crianças de sete e oito anos frente à imagem de Rua de Erradias:

- Tem um homem e quatro mulheres. As duas que estão na janela estão olhando para fora. As outras duas da frente também estão olhando. $O$ homem está olhando para as duas mulheres que estão na janela, porque ele achou elas bonitas.

- As mulheres estão passeando. Estão visitando uma casa velha; uma tia delas que mora nesta casa, porque elas estavam com muita saudade.

- Tem uns olhando as pessoas caminharem. Elas vão num lugar, num amigo ou na sorveteria.

- São pessoas de máscara. Botaram as máscaras para brincar. Não, eu acho que elas vão pegar um livro e vão sentar no sofá para ler. Quando elas vão ler, tiram as máscaras.

Segundo estudiosos do desenvolvimento, a partir dos seis anos, aproximadamente, as crianças têm facilidade de lidar mentalmente com problemas, "mas esses problemas lidam com entidades concretas" (GARDNER; KORNHABER; WAKE, 1998, p. 123). É o que se vê no diálogo a seguir, pois não foram atribuídos sentidos de natureza metafórica ou abstrata - como é frequente a partir dos 11/12 anos aproximadamente. As crianças enfocaram os aspectos 
mais concretos da cena. Segundo Freeman e Sanger (1995) essa é uma leitura "realística" - ligada ao real como algo concreto. Mais tarde aparecerá a leitura "mentalística", que considera o papel da intencionalidade do artista na sua produção. É quando os leitores passam a ver possibidades de sentidos para os signos presentes na obra, transcendendo os aspectos concretos imediatamente visíveis.

Neste diálogo frente à imagem de Narciso ainda não aparece a ideia de que o artista tem autonomia para usar símbolos ou metáforas para expressar algo que não está ali, visivelmente, concretamente:

Figura 1 - Caravaggio, Narciso na fonte, 1596. Óleo sobre tela.

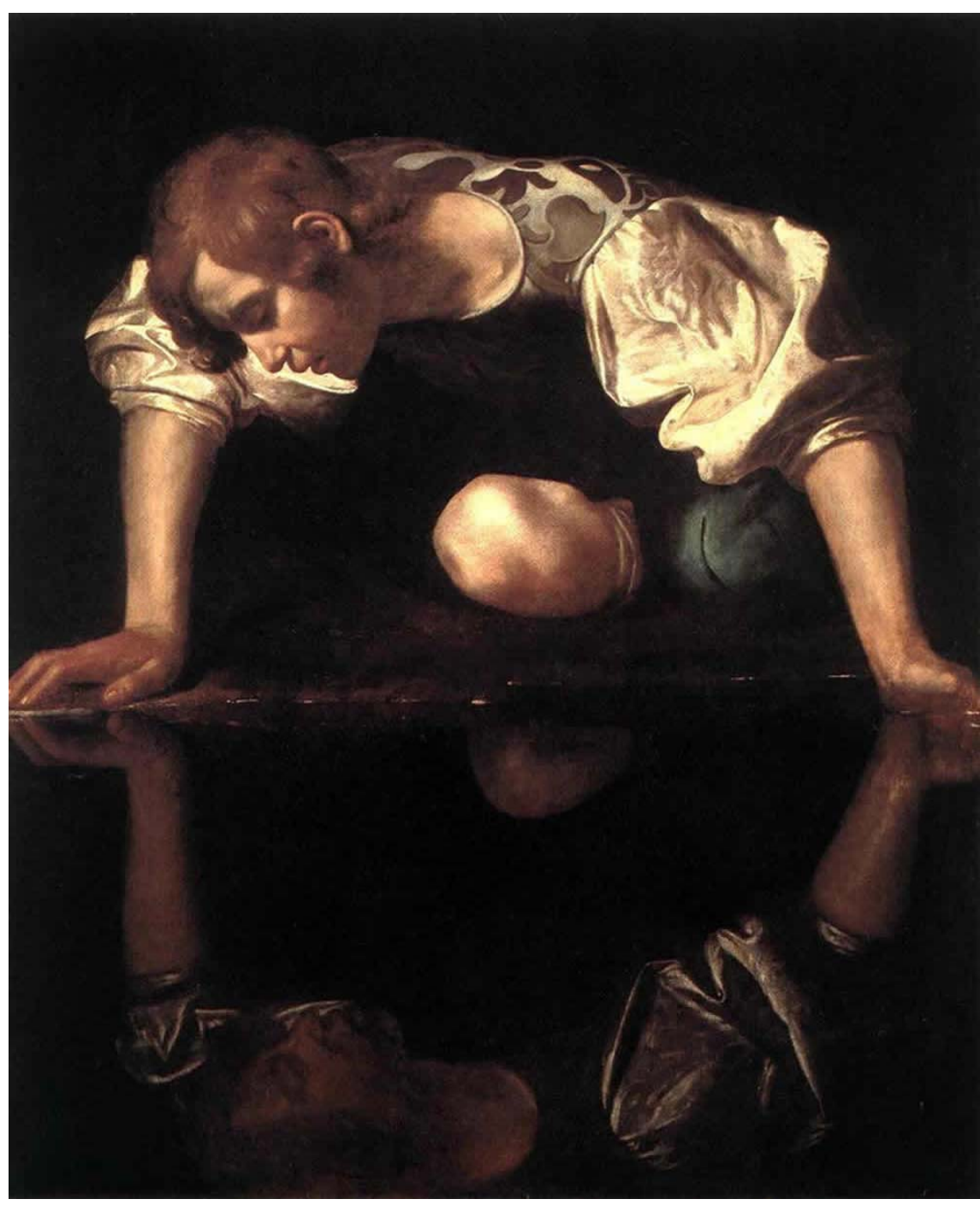

Fonte: Galleria Nazionale d'Arte Antica. 
Professora - Vamos falar sobre esta imagem?

Cás ${ }^{9}$ - É uma mulher que está com uma jaquetona e que está subindo em cima da mesa.

$\mathrm{Fel}$ - A mulher tem alguma coisa nas costas, ali perto do pescoço.

Professora - E o que você acha que é isso?

Fel - Deve ser alguma coisa da blusa.

Cás - É o couro de tigre.

Professora - Você acha que pode ser isso, Felipe? Por quê?

$\mathrm{Fel}$ - Não sei, deve ser.

Tho - Eu acho que é um homem e ele está ajoelhado no chão. O chão está lustro, por isso que ele vê o reflexo. E aparece o joelho dele.

Professora - Então não é uma mesa e sim o chão?

Cam - É menino ou menina?

Professora - O que você acha que é?

Cam - Eu acho que é homem. E ele está com as mangas arregaçadas.

Arl - Eu estou vendo uma pessoa que está olhando para a água e eu acho que ela vai beber a água.

Professora - Vejam que surgiu outra ideia: não é uma mesa nem o chão.

É água?

BrP - Parece que o homem está olhando para baixo e tem uma mesa bem limpinha. Ele está subindo em cima da mesa para olhar na água.

Professora - Ah, então ele vai subir na mesa para olhar a água? Ou beber? Será que ele está olhando a água ou o reflexo dele mesmo?

$\mathrm{BrD}$ - Ele está ajoelhado ou está em cima da mesa?

Car - Eu acho que é uma mulher. Ela está com um vestido verde e tem o cabelo meio curto e está olhando o seu reflexo na água.

Luc - Este cara está olhando para a água e se olhando no espelho da água, que é o reflexo.

Professora - Todo mundo ouviu o que a Caroline e Lucas falaram? Ele está olhando o seu reflexo na água. Podem ver?

Luc - Dá para ver!

Cri - Eu acho que é uma mulher ajoelhada se olhando no chão lustro.

Lau - Não pode estar ajoelhado, porque não tem a outra parte da perna.

Flá - É uma foto ou um livro?

Luc - É pintura.

Professora - Isso mesmo! É uma pintura. Só que eu fotografei num livro. Mas foi feita com pincel e tinta.

Arl - Aquilo ali é uma mesa ou água?

Professora - Quem vai responder?

Mau - É água.

BrP - É vidro.

Tom - Água poluída.

Cás - É água.

Professora - Quem acha que é água? Quem acha que é chão lustro? [A maioria acha que é água] $E$ quem acha que é espelho? [A maioria confirma que é água].

May - Que ano foi pintado?

${ }^{9}$ Neste excerto de leitura os nomes das crianças estão codificados com três letras. 
Crianças - 1939. 1990. 1960. 1963. 1950. Deve ser um pouquinho mais que o século XVIII. 1500.

Professora - 1500! Quase! Por que você acha que foi em 1500?

Luc - É porque eu vi o cara, o tipo da roupa, os cabelos.

Professora - Isso mesmo! Foi em 1596, mas você quase acertou em cheio!

BrP - Ele está dormindo ou vai cair na água?

Cam - Eu acho que ela está no navio que descobriu o Brasil e está se olhando numa poça de lama.

Car - Quem pintou?

Professora - Quem sabe o nome do artista?

$\mathrm{BrP}$ - Pablo Picasso.

Professora - Se o Pablo Picasso pintou aquelas mulheres na praia, que vimos na semana passada, em 1920, como ele pintaria este em 1596?

Ele já existia?

Crianças - Não! Então quem foi?

Professora - O nome deste pintor é Caravaggio.

Lau - Cadê a outra parte da perna dele?

Car - Eu acho que ela está com o joelho debaixo do vestido.

Cri - Ela é homem ou mulher?

Car - Já fizeram esta pergunta; ela é mulher!

Professora - Então, quem acha que é uma mulher? [sete]. Quem acha que é homem? [a maioria]. A maioria acha que é um homem!

Lau - Ele não pode ficar assim. Tem que aparecer a outra parte.

Professora - Mas não aparece. Por que será que está assim?

Bru - O que é aquela bola verde?

Professora - Onde tem bola? Ah, aqui? [aponto o joelho esquerdo de Narciso] Isso é uma bola?

Cam - Não é uma bola, é um vaso.

Tho - Eu acho que ele dobrou a bermuda para não doer o joelho.

Cás - Eu acho que o outro joelho está embaixo da mesa.

Cam - O que é aquilo lá? Parece um bicho pousado no ombro.

Tho - Eu acho que a roupa dele está meio suja.

Lau - Não pode ser uma mesa, porque como é vai ter uma mesa e um lago do lado? Está mais parecido que ele está ajoelhado numa terra e olhando para o rio.

Cri - É um chão listrado.

Luc - Ele está dormindo ou acordado?

Lui - Ele está acordado.

Tom - Ele está acordado e olhando para água.

Tho - Eu acho que ele tomou champanhe e ficou bêbado.

Cam - Eu acho que ele ficou enjoado.

Professora - Todos concordam que ele está acordado?

Crianças - Sim!

Professora - Eu concordo que ele está acordado, se olhando na água, porque dá para ver o olho aberto aqui no reflexo. Podem ver?

Tho - O que é aquilo que tem nas costas dele?

Cás - Parece couro de tigre.

BrD - É tipo um escudo de guerra.

Cam - É uma capa. 
Tho - Eu acho que ele é um deficiente.

Professora - Por que você acha isso? Você acha que pode ser um colete para deficiente? Será, gente?

Lui - É uma capa, tipo, para proteger.

$\mathrm{Fel}$ - Parece que é um emblema nas costas.

Flá - É uma camiseta.

May - É uma fantasia de tartaruga.

Professora - O que vocês acham? Será que não era uma roupa comum naquela época?

Cam - Ele está num navio ou em terra firme?

Tho - Numa balsa!

$\mathrm{Fel}$ - As cores do fundo são mais escuras. Parece que ele está num mato. Professora - O Felipe falou das cores. Quais são as cores que estão aqui? Pode ser cores de um mato?

Eli - Marrom, preto.

Lui - Verde, marrom e cor da pele.

Professora - Então ele poderia estar num mato mesmo, não é?

[...]

Professora - Vocês acham que esta é uma boa imagem?

Cri - Não é boa, porque é muito escuro e está muito mal pintado.

May - Porque tem muito preto.

Gab - Não tem cores alegres.

Lau - Eu concordo.

Car-E porque parece que ele está chorando.

Cam - E que só tem o branco de mais alegre.

Nat - É mais ou menos...

Tho - Essa imagem é ridícula, não tem nada a ver, porque a capa dele é extravagante.

Tom - É porque é de noite e feio!

Mau - Não tem muitas cores.

Lui - Ela é feia, não dá para ver se é chão ou água.

$\mathrm{Fel}$ - Não tem cores alegres, só tem cores tristes. E parece que ele está morto, deitado e bêbado.

Cás - Tem poucas cores alegres e o pintor não continuou a imagem.

Luc - Eu não acho boa, porque esse homem é aleijado, só tem um joelho e ainda bem pequeninho.

Professora - Quem acha que é uma boa imagem? Ninguém acha? Todos acham ruim?

Crianças - Sim!

Cam - Você acha que é uma boa imagem?

Professora - Eu acho!

Cam - Por quê?

Professora - Eu acho que é boa. É interessante de olhar e descobrir do que ela trata; se é um homem ou uma mulher; o que ele está fazendo ali...10

${ }^{10}$ Esta resposta mostra que o papel do professor/mediador não é ser a autoridade que sabe todas as respostas corretas. É mais profícuo ser mais uma voz a se manifestar, mas não a única, 
O que aprender, nesse diálogo, sobre a compreensão estética de crianças? Se prestarmos atenção, podemos entender a natureza do pensamento estético no início da vida escolar. Os depoimentos mostram uma compreensão realística da arte (FREEMAN; SANGER, 1995). Implicitamente revelam que as crianças creem que a arte mostra as coisas (que devemser boas e bonitas) que existem ou acontecem; e que isso deve ser feito com realismo, maestria e cores alegres. Para justificarem que "a imagem não é boa" usaram os argumentos: é muito escuro e está muito mal pintado; tem muito preto; não tem cores alegres; parece que ele está chorando; só tem o branco de mais alegre; a capa dele é extravagante; é de noite e feio; não dá para ver se é chão ou água; parece que ele está morto, deitado e bêbado; esse homem é aleijado, só tem um joelho e ainda bem pequeninho...

Freeman e Sanger (1995) explicam que, nessa compreensão, o leitor relaciona a obra com o mundo nela representado e não com a mente criadora do artista. É uma ideia coerente com o surgimento de narrativas, tais como: ele está subindo em cima da mesa para olhar na água... está olhando para a água e eu acho que ela vai beber a água... ele tomou champanhe e ficou bêbado...

Pode-se notar que as crianças tentam identificar os elementos ou coisas que veem. Quando algo não é reconhecido, vão criando hipóteses e propondo alternativas interpretativas. Não é, ainda, como fazem os alunos mais velhos nos anos finais do ensino fundamental, que buscam possibilidades mais simbólicas e metafóricas, próprias da compreensão mentalística (FREEMAN; SANGER, 1995). Por exemplo, as crianças queriam "descobrir" onde Narciso estava ajoelhado, e surgiram estas alternativas de interpretação: mesa, vidro, chão, terra e água. E, além de discutirem se o personagem é homem ou mulher (não houve consenso), também queriam decifrar o que ele veste: "o que é aquilo que tem nas costas dele?". Algumas ideias foram: jaquetona, couro de tigre, escudo de guerra, colete para deficiente, uma capa, camiseta, fantasia de tartaruga... Segundo Parsons e Blocker (1993), todos nós - inclusive as crianças - nos perguntamos sobre os fatos que não se encaixam em nossas concepções de

certa ou verdadeira, pois "o dogmatismo é um inimigo da filosofia" (PARSONS; BLOCKER, 1993, p. 165). 
realidade, e esses questionamentos têm caráter filosófico. Portanto, a criança e a filosofia não são incompatíveis e a leitura visual pode se beneficiar disso.

Além desses autores, Matthew Lipman (1990) pode embasar uma defesa para trazer a filosofia na leitura visual. Talvez não seja fácil admitir que um diálogo tão "infantil" como esse frente à imagem de Narciso seja repleto de pensamento crítico e reflexivo sobre arte, pois relacionamos as palavras filosofia, estética e teoria com a retórica sofisticada do adulto. Mas admitir essa ideia pode ser um bom começo para repensar a educação estética das crianças.

A partir dos anos finais do ensino fundamental, os alunos têm "facilidade para pensar sobre um mundo constituído por pensamentos, ideias e conceitos" (GARDNER; KORNHABER; WAKE, 1998, p. 123), ampliando sobremaneira o horizonte da ação educativa com a leitura visual. O aluno usa suas habilidades formais para fazer hipóteses sobre possíveis sentidos das imagens. Estar atento ao surgimento das ideias mentalísticas permitirá ao professor/mediador explorar a discussão estética em um nível mais complexo e abrangente. Um leque de perspectivas se abre para enriquecer a educação estética quando as crianças reconhecem a intencionalidade do artista ${ }^{11}$. Entender que a arte trata de temas e que o artista usa os signos da arte para dizer algo, para expressar ideias, representa um avanço no processo do desenvolvimento estético, que pode enriquecer a compreensão de mundo do aluno a partir do $3^{\circ}$ ciclo do ensino fundamental, desde que ele tenha oportunidades de pensar sobre arte.

\section{Considerações finais}

A leitura visual com discussão estética pode ser lúdica, dinâmica, surpreendente - porque não padronizada - desafiando os alunos para a abertura, para a exploração de diferentes caminhos, para a aceitação de múltiplos pontos de vista, para a invenção, a colaboração, a aprendizagem pelos pares, a autonomia... elementos esses que atendem aos modos de ser do aluno contemporâneo - mesmo os da geração zappien.

\footnotetext{
11 Isso não é o mesmo que a criança dizer: o artista fez assim porque quis; porque ele viu e quis mostrar, ou outras falas de cunho mais retórico do que conceitual.
} 
O recorrente objetivo da educação - "desenvolver o espírito crítico e a autonomia dos estudantes" - nem sempre se efetiva, pois é preciso pôr em prática/ação as habilidades para a crítica: pensar, decidir, refletir, avaliar etc. Mas pode-se afirmar que pensar sobre arte é um modo eficiente (e cativante) de desenvolver a criticidade e a autonomia. Sem aprofundar esse argumento, defendemos que o momento da leitura visual na sala de aula proporciona as condições para o desenvolvimento desse importante objetivo educacional. É um momento em que o aluno pode expor suas ideias (por autoria e não por reprodução), considerar (avaliar) outras ideias sobre o mesmo objeto, mudar de ideia (se considerar plausível) ou ratificar as suas (quando julgar adequado), além de questionar e ser questionado. E tudo isso sem que ele seja corrigido por não acertar a resposta esperada pelo professor. Como diz Larrosa:

\begin{abstract}
Continuo firmemente convencido de que a educação tem a ver com construir sujeitos que sejam capazes de falar por si mesmos, pensar e atuar por si mesmos. Não diria tanto em ser os donos de suas próprias palavras, porque as palavras não têm dono, mas sujeitos que sejam capazes de se colocar em relação com o que dizem, com o que fazem e com o que pensam. Eu não estou certo de que isso seria autonomia. Mas sei que continuo firmemente convencido de que a educação, se é emancipadora em algum sentido, tem a ver com dar as pessoas a capacidade de pensar por si mesmas. (2013, s/p).
\end{abstract}

A leitura visual pode contribuir nessa educação emancipadora de que fala Larrosa, ao proporcionar oportunidades para os estudantes pensarem sobre arte - por si mesmos, já que, como dito acima, criança e filosofia não são incompatíveis e os questionamentos de uma discussões estética têm caráter filosófico. Mas considerando que não é qualquer leitura ou discussão estética que serve para todos, é compromisso do professor/mediador estar atento a cada contexto de sua atuação. Se na educação infantil determinado tipo de imagem não gera conversas tão dinâmicas, nos anos iniciais elas podem ser adequadas. Para saber o que é mais adequado e pertinente no processo do desenvolvimento da compreensão estética do aluno, é preciso escutá-lo e aprender como ele constrói conhecimento. As ideias intuitivas ("teorias", segundo Freeman e Sanger) que os alunos vão construindo e expressando durante a leitura visual são o melhor guia para os roteiros das leituras. Assim, o professor poderá adequar a seleção das imagens e das perguntas das leituras que propõe, no sentido de provocar questionamentos que gerem novas reflexões, novos modos 
de conceber as produções artísticas, enfim, novas compreensões sobre arte que possam enriquecer a vida dos alunos.

\section{Referências}

COUCHOT, Edmond. A arte pode ainda ser um relógio que adianta? $\mathrm{O}$ autor, a obra e $\mathrm{O}$ espectador na hora do tempo real. In: DOMINGUES, Diana (Org.) A arte no século XXI: a humanização das tecnologias. São Paulo: UNESP, 1997.

DEBRAY, Régis. Vida e morte da imagem. Petrópolis: Vozes, 1993.

DOMINGUES, Diana. A humanização das tecnologias pela arte. In: DOMINGUES, Diana (Org.). A arte no século XXI: a humanização das tecnologias. São Paulo: UNESP, 1997.

FRAGOSO, Graça Maria. O livro, a biblioteca e a primeira infância: trilogia do afeto. Presença Pedagógica, v. 4, n. 22, p. 44-51, jul./ago. 1998. Disponível em: https://www.yumpu.com/ pt/document/view/15284450/o-livro-a-biblioteca-e-a-primeira-infancia-presenca-pedagogica.

Acesso em: jan. 2014.

FREEMAN, Norman H.; SANGER, Daniela. The commonsense aesthetics of rural children. Visual Arts Research, v. 21, n. 2, p. 1-10, 1995.

GARDNER, Howard; KORNHABER, Mindy L.; WAKE, Warren K. Inteligência: múltiplas perspectivas. Porto Alegre: Artes Médicas, 1998.

HOUSEN, Abigail, The eye of the beholder: measuring the aesthetic development. Tese. (Doutorado em Educação) - Faculdade de Educação, Harvard University, Cambridge, EUA, 1983.

KESSELRING, Thomas. Ética e educação. Caxias do Sul: UCS, 22 maio. 2011. Palestra ministrada no Fórum de Licenciaturas da UCS.

LARROSA, Jorge. O papel da educação é subverter as regras. São Paulo: 2013. Portal Aprendiz. Entrevista concedida a Camila Caringe. Disponível em: http://portal.aprendiz.uol.com.br/2013/04/09/o-papel-da-educacao-e-subverter-as-regras.

Acesso em: 20 out. 2014.

LIPMAN, Matthew. A filosofia vai à escola. São Paulo: Summus, 1990.

LUQUET, Georges-Henri. El dibujo infantil. Barcelona: Médica y Técnica, 1981.

OLIVEIRA, Ana Cláudia M. A. Convocações multissensoriais da arte no século XX. In: PILLAR, Analice Dutra (Org.). A educação do olhar no ensino das artes. Porto Alegre: Mediação, 1999.

PANOZZO, Neiva S. P.; RAMOS, Flavia B. Entre a ilustração e a palavra: buscando pontos de ancoragem. Espéculo, Madri, ano IX, n. 26, mar./jun. 2004. Disponível em: <https://pendientedemigracion.ucm.es/info/especulo/numero26/ima_infa.html>. Acesso em: 18 out. 2014.

PARSONS, Michael J. Compreender a arte: uma abordagem à experiência estética do ponto de vista do desenvolvimento cognitivo. Lisboa: Presença, 1992.

PARSONS, Michael J; BLOCKER, H. Gene. Aesthetics and education. Chicago: University of Illinois, 1993.

PARSONS, Michael J; FREEMAN, N. Children's intuitive understanding of pictures. In: TORFF, Bruce; STERNBERG, Robert J. (Eds.). Understanding and teaching the intuitive mind. Londres: Erlbaum, 2001. p. 73-91.

ROSSI, Maria Helena Wagner. Imagens que falam: leitura da arte na escola. Porto Alegre: Editora Mediação, 2003.

ROSSI, Maria Helena Wagner. A estética no ensino das artes visuais. Educação \& Realidade Dossiê Arte e Educação: arte criação e aprendizagem, Porto Alegre, v. 30, n. 2, p. 49-69, jul./dez. 2005. 
ROSSI, Maria Helena Wagner. O desenvolvimento do pensamento estético no ensino fundamental. In: BARBOSA, Ana Mae; COUTINHO, Rejane Galvão. (Orgs.). Arte/educação como mediação cultural e social. São Paulo: Editora UNESP, 2009.

ROSSI, Maria Helena Wagner. Reflexões sobre a mediação estético-visual: como estimular o encontro com a obra? In: ENCONTRO INTERNACIONAL DIÁLOGOS EM EDUCAÇÃO, MUSEU E ARTE, 2010, Porto Alegre. Anais... Porto Alegre, Santander Cultural, Pinacoteca do Estado de São Paulo, 2010. Disponível em: http://www.museuparatodos.com.br/museuparatodos. Acesso em: 21 jun. 2014.

VEEN, Wim; VRAKKING, Ben. Homo zappiens: educando na era digital. Tradução de Vinícius Figueira. Porto Alegre: Artmed, 2009.

VEEN, Wim. Homo zappiens and the need for new education systems. The Netherlands: Delft University of Technology Faculty of Technology, Policy and Management. s/d. Disponível em: http://www.oecd.org/edu/ceri/38360892.pdf. Acesso em: 25 jul. 2015.

\section{Maria Helena Wagner Rossi}

Doutora em Educação pela Universidade Federal do Rio Grande do Sul. Mestre em Educação pela UFRGS. Cursou Licenciatura em Desenho e Plástica na UFRGS. É professora de Arte aposentada da rede estadual de ensino do Rio Grande do Sul. É professora/pesquisadora na Universidade de Caxias do Sul (UCS). É líder do Grupo Interdisciplinar Arte, Cultura e Patrimônio - CNPq/UCS e vice-líder do Grupo de Pesquisa em Educação em Arte (GEARTE) CNPq/PPGEDU/UFRGS. É vice-presidente da FAEB (Federação de arte-educadores do Brasil) no biênio 2014-2016. Tem publicado artigos em revistas e capítulos de livros sobre leitura de imagens e compreensão estética visual. É autora do livro Imagens que falam: leitura da arte na escola, publicado pela Editora Mediação em 2003 (5ª edição: 2011; PNBE: 2011).

E-mail: mhwrossi@gmail.com

Currículo: http://lattes.cnpq.br/5017888754814808 